\begin{tabular}{|l|l|l||}
\hline \multicolumn{2}{|c|}{ PublisherInfo } \\
\hline \hline PublisherName & $:$ & BioMed Central \\
\hline \hline PublisherLocation & $:$ & London \\
\hline \hline PublisherImprintName & $:$ & BioMed Central \\
\hline \hline
\end{tabular}

\title{
Dobutamine in the postbypass period
}

\begin{tabular}{|l|l|l||}
\hline \multicolumn{2}{|c||}{ ArticleInfo } \\
\hline \hline ArticleID & $:$ & 4167 \\
\hline \hline ArticleDOI & $:$ & $10.1186 /$ ccf-1999-2261 \\
\hline \hline ArticleCitationID & $:$ & 2261 \\
\hline \hline ArticleSequenceNumber & $:$ & 26 \\
\hline \hline ArticleCategory & $:$ & Paper Report \\
\hline \hline ArticleFirstPage & $:$ & 1 \\
\hline \hline ArticleLastPage & $:$ & 4 \\
\hline \hline & & RegistrationDate : 1999-11-19 \\
ArticleHistory & $:$ & OnlineDate $\quad$ 1999-11-19 \\
\hline \hline ArticleCopyright & $:$ & Current Science Ltd1999 \\
\hline \hline ArticleGrants & $:$ & \\
\hline \hline ArticleContext & $:$ & 1305422 \\
\hline \hline
\end{tabular}




\section{Keywords}

Aortocoronary bypass, heart

\section{Comments}

This paper's main interest is that it demonstrates that drugs may have different effects in different clinical situations. The observed effects of dobutamine were different to those expected, but the cardiac loading conditions after CPB differ enormously from those in cardiogenic shock or in the ICU, where the drug has previously been studied. The results suggest that the improvements in cardiac performance are wholly due to increasing heart rate and, presumably, myocardial oxygen requirement, which may well be undesirable in these patients. It suggests that further useful work could be performed to evaluate other inotropes in the post CPB period.

\section{Introduction}

This study investigates the effect of dobutamine on cardiovascular performance in the period following separation from cardiopulmonary bypass (CPB). This period is associated with haemodynamic instability, rapid changes in ventricular loading and myocardial perfusion, and changes in global or regional ventricular function.

\section{Aims}

To extend the dobutamine dose response range, to evaluate ventricular perfomance by transoesphageal echocardiography (TEE), and to provide information on dosing strategies for coronary artery bypass raft $(\mathrm{CABG})$ patients.

\section{Methods}


A total of 121 patients for CABG were enrolled in the study. Patients with preoperative inotrope requirement or contraindication to TEE were excluded. Standard intraoperative monitoring was used and the information downloaded to a laptop computer. Multidose cold cardioplegia was used during the case. Short axis midpapillary TEE was used to determine the left ventricular end systolic area (ESA), end diastolic area (EDA), fractional area change (FAC) and two dimensional estimate of ejection fraction. Baseline haemodynamic data and TEE images were obtained within $10 \mathrm{~min}$ of cessation of CPB and then the subjects received sequential 3 min dobutamine infusions of 5, 10, 20, 30 and 40 ?g/kg/min. Haemodynamic data were recorded at the end of each 3 min period. If tachycardia or signs of ischaemia developed then the infusion was stopped. During the infusion, all surgical manipulations were stopped. Ten patients acted as controls, receiving no dobutamine infusion. Data were analysed to assess the interplay of covarients (eg age) on the observed response.

\section{Results}

Heart rate increased in a dose-dependent manner with dobutamine, and was most rapid in those patients who did not reach the maximum dose. The heart rate response was less marked in older individuals. There was minimal change in blood pressure, but slightly decreased pulmonary capillary wedge pressure (PCWP) and central venous pressure (CVP). Systemic vascular resistance (SVR) increased very slightly at low doses and remained constant at larger doses. Left ventricular performance increased due to an increase in heart rate (stroke volume index decreased).

\section{Discussion}

In this group of patients, dobutamine administered in the immediate postbypass period improved cardiac performance by increasing heart rate. This increased heart rate is not consistent with other studies but may be due to depression of the baroreceptor reflex in anaesthetised subjects. The slight increase in SVR observed is contradictory to the findings of other studies; however, the patients in this study were vasodilated after CPB and therefore had a pre-existing low SVR. It was also found that systolic blood pressure did not alter with the dobutamine, possibly due to the fact that CVP and PCWP both fell slightly. Whilst TEE measurement of FAC indicated improved cardiac performance, there was a substantial increase in heart rate which may have been detrimental in terms of myocardial oxygen requirement.

Several limitations of this study exist: firstly, the time period of investigation was short, and secondly, cardiac performance may have been changing during the post CPB period. Importantly, cardiac loading was not kept constant and, had it been, improvements in cardiac performance might have been seen. 


\section{References}

1. Romson JL, Leung JM, Bellows WH, Bronstein M, Keith F, Moores W, Flachsbart K, Richter R, Pastor D, Fisher DM: Effects of dobutamine on hemodynamics and left ventricular performance after cardiopulmonary bypass in cardiac surgical patients. Anesthesiology. 1999, 91: 1318-1328.

This PDF file was created after publication. 